\title{
Bemiparin versus low dose aspirin for management of recurrent early pregnancy losses due to antiphospholipd antibody syndrome
}

\author{
Shahla Alalaf
}

Received: 17 January 2011/Accepted: 1 August 2011/Published online: 13 August 2011

(C) The Author(s) 2011. This article is published with open access at Springerlink.com

\begin{abstract}
Study objective To compare the live birth rate of women presented with recurrent miscarriages in the first trimester due to antiphospholipid antibody syndrome (APS), randomized to either low molecular weight heparin (Bemiparin) or low dose aspirin (LDA) and to determine the maternal and fetal adverse effects in both treatment groups. Patients and methods A clinical comparative study was conducted in Maternity teaching Hospital, Erbil city, north of Iraq, Kurdistan region from 15th of September 2007 to the 1st of August 2010 on 141 women presented with 2 or more consecutive miscarriages due to APS, the women randomized to receive either prophylactic dose of Bemiparin with the diagnosis of pregnancy or LDA started preconceptioally and until 36 weeks gestation. The primary outcome was live birth rate in both treatment groups, the secondary outcomes were maternal and fetal complications in both trial groups.

Result There was no statistically significant difference between the two groups regarding demographic characters (age groups, parity, gestational age and history of previous abortion), and mode of delivery of the viable newborns. There was a statistically significant difference between the two treatment groups regarding live birth rate. The proportions of women who gave birth to a live infant were $72.13 \%$ in the LDA group and $86.25 \%$ in the Hibor group, the mean difference between the live birth rate in both group was 0.141 (95\% Confidence interval of the difference, $0.08,0.274)$. The average birth weight for women received LDA was significantly lower than women who received Bemiparin.
\end{abstract}

S. Alalaf $(\bowtie)$

Department of Obstetrics and Gynecology, College of Medicine,

Hawler Medical University, Erbil, Kurdistan, Iraq

e-mail: Shahla_alaf@yahoo.com; shahla.alaf@yahoo.com
Conclusion The use of the new second generation LMWH (Bemiparin) in comparison to LDA during pregnancy for prevention of recurrent miscarriage in women with APS is a safe, reliable method with a high live birth rate and no maternal and fetal complications.

Keywords Recurrent miscarriage - Low molecular weight heparin - Bemiparin - Hibor - Low dose aspirin

\section{Introduction}

Recurrent miscarriage (RM) is traditionally defined as three or more consecutive miscarriages occurring before 20 weeks post-menstruation [1]. The American College of Obstetrician and Gynecologists has recently stated that the causes of recurrent fetal losses are similar in women who have suffered two losses or more when compared with women who have had three losses [2]. Approximately $1 \%$ of all women trying to conceive have RMs; when RM is defined as two previous miscarriages, the proportion rises to 5\% [3]. They may or may not follow a successful birth. About half of RMs are unexplained [4]. Medical investigations usually begin after a third loss, but some centers investigate after two losses on the basis that the risk of failure in the next pregnancy increases substantially [5].

The European Society of Human Reproduction and Embryology (ESHRE) Special Interest Group for Early Pregnancy (SIGEP) protocol for the investigation and medical management of RM, based on the data of recently published large randomized controlled trials (RCTs) and meta-analysis, recommended that basic investigations of a couple presenting with RMs should include obstetric and family history, age, BMI, and exposure to toxins, full blood count, antiphospholipid antibodies (lupus anticoagulant 
and anticardiolipin antibodies), parental karyotype, pelvic ultrasound and/or hysterosalpingogram [6]. The most compelling association between pregnancy loss and autoimmune phenomena has been with the presence of antiphospholipid antibodies-Lupus anticoagulant and anticardiolipin antibody [7]. Antiphospholipid antibody syndrome is an autoimmune disease characterized by the presence of antiphospholipid antibodies and at least one clinical manifestation, the most common being venous or arterial thrombosis and recurrent fetal loss. The syndrome occurs in isolation, or in association with connective tissue diseases, particularly systemic lupus erythematosus [8]. It may coexist with several, predominantly autoimmune diseases [9].

Pregnancy loss associated with antiphospholipid antibodies (aPL) has traditionally been ascribed to thrombosis of the utero-placental vasculature [10]; however, thrombosis is neither a universal nor a specific finding in aPL pregnancies [11].

Management of APS focuses on anticoagulation; however, despite the solid evidence suggesting that this is the best treatment option available, a lot of debates persist regarding the intensity and duration of anticoagulation needed in various subsets of APS. Thus there are currently no uniformly agreement upon management algorithm for APS [12]. Although several treatments have been advocated, heparin and aspirin treatments are emerging as the treatment of choice for APA syndrome associated with recurrent pregnancy loss [13].

Dawes et al. [14] demonstrated that low molecular weight heparin (LMWH) may be more effective than unfractionated heparin, because it is more effectively absorbed after subcutaneous administration and has a longer half life in the circulation. This represents an important role for LMWH in the treatment of APS in pregnancy, because it causes less bleeding in both vaginal and abdominal deliveries [15].

Many types of LMWH have been used alone or in combination with aspirin low dose with different results in different settings for prevention of miscarriages associated with APS, but the current study is regarded as the first one using the new second generation LMWH (Bemiparin) alone as a trial for prevention of RM due to APS.

\section{Objectives}

The primary outcome measure was to compare the live birth rate in women presented with RM due to APS treated with LMWH versus aspirin low dose, secondary outcomes included obstetrical complications, fetal and maternal adverse events in both treatment groups.

\section{Patients and methods}

A clinical comparative study was performed to investigate whether treatment with LMWH versus ALD results in increased live birth rate in women with history of RPL and APS, in Maternity Teaching Hospital, Erbil city, Kurdistan region, North of Iraq from 15th of September 2007 to the 1st of August 2010.

\section{Participants}

\section{Inclusion criteria}

Women considered participants in this trial fulfilled the following criteria: aged 18-42 years at the time of interview; a history of $\geq 2$ unexplained consecutive pregnancy losses before 20 weeks gestation; persistent presence of anticardiolipin antibodies and or Lupus anticoagulant in two occasions 8 weeks apart.

\section{Exclusion criteria}

The included Systemic Lupus Erythematosus, known peptic ulcer disease, sensitivity to Aspirin or Heparin depending on patients' history report, previous venous thromboembolic disease requiring ongoing anticoagulant therapy and failure to consent to participate.

Cases with SLE were excluded from the study because pregnant mothers with SLE should remain under medical care until delivery, they have an extra increased risk for pregnancy complications, usually they are on multiple medications depending on the system involved by the disease (patients require warfarn or cyclophosphamide therapy should not get pregnant), they may be on Nonsteroidal antiinflammatory drugs, Anti-malarial drugs, glucocorticoids, or immunosuppressive drugs like methotrexate. SLE may flare up during pregnancy and has its own complications regarding the fetus and newborn babies.

Other causes for RM were regarded as exclusion criteria. Hormonal assay was carried out to exclude polycystic ovarian syndrome and thyroid dysfunction, hysterosalpingogram/Ultrasound was done to exclude anatomical causes for RM, cervical cultures for mycoplasma and urea plasma to exclude bacterial vaginosis infection. To exclude frank diabetes as a risk factor for RM, glucose tolerance test was done for suspicious cases, karyotype analysis for both parents was done for both parents depending on a local laboratory in the city which was available recently in our city, and other cases we depend on the results done abroad by the patients themselves.

Only one case with type 1 diabetes mellitus was not excluded from the study being a case with strictly 
controlled blood sugar with a high level of anticardiolipin antibody titer in two occasions.

\section{Laboratory evaluation}

To confirm the diagnosis of APS in the participant, positive serology was defined as at least one of the following tests to be positive in two occasions:

1. Anticardiolipin antibodies in medium to high titer levels were identified using a standardized enzymelinked immunosorbent assay (ELISA) IgG $>15 \mathrm{IgG}$ phospholipids units (GPL) or IgM $>25$ IgM phospholipids units (MPL).

2. Lupus anticoagulant measured by prolonged phospholipid-dependent coagulation (aPTT, Kaolin clotting time, dilute Russell viper venom test, dilute PT), the prolonged coagulation time was failed to be corrected by a mix with platelet poor plasma and the prolongation of coagulation time was also corrected with excess phospholipids [16].

3. Anti- $\beta 2$ glycoprotein $1 \mathrm{IgG}$ and/or IgM isotype in serum or plasma is also regarded as one of the criteria for diagnosis of APS, it was not done in the current trial because the method was not available in our city and to diagnose APS at least one of the clinical criteria and only one of the laboratory criteria should be met.

\section{Sample size}

The sample size consists of 146 ladies presented to the maternity teaching hospital, with RM, clinical and laboratory evaluation done for all the cases; all known causes for RM were excluded except for APS and they were asked to attained the hospital as soon as they miss a period of their menstrual cycle. Both groups were advised to use prenatal folic acid, the LDA group women were given the drug assuming that the pregnancy occurs if she was not using any contraception. The study time was about 3 years and most of patients got pregnant within this period of time except five cases who were referred to a special infertility unit in the maternity teaching hospital. Sixty-one cases were randomly assigned to receive Low Dose Aspirin (LDA) before pregnancy was diagnosed at suspected month and continued throughout pregnancy till 36 weeks gestation, the other group of 80 cases were assigned to receive LMWH (Bemiparin) with the diagnosis of pregnancy. Pregnancy in both groups was confirmed by either two rising quantitative beta human chorionic gonadotropin ( $\beta \mathrm{hCG}$ ) hormone $48 \mathrm{~h}$ apart or by ultrasound confirming fetal heart activity, randomization to the treatment group done using alternative criteria, the 1 st case attained the hospital complaining from RM and proved to have APS, was randomized to LDA group, the second case attained the hospital and full filled the inclusion criteria; LMWH was prescribed to her, sometimes two cases of Heparin followed one case of LDA. All the cases received the drug randomly.

\section{Clinical assessments}

All women in the two treatment groups were evaluated every 6 weeks during their pregnancy. The assessment included detailed history, obstetrical and general examination, a specially designed questionnaire to record the obstetrical data at each visit, fetal development and wellbeing as well as maternal complications. Delivery information was obtained from the obstetrician on call at the time of labor for cases which delivered spontaneously vaginally, and cases which delivered abdominally.

Side effects of both medications were asked for by each woman and recorded in the same questionnaire.

The trial drugs

Bemiparin sodium (Hibor; Laboratories Rovi Pharmaceuticals, a Spanish integrated and specialist company) is a LMWH with a lower mean molecular weight $(3,600 \mathrm{D})$ and a higher anti-FXa/F11a ratio (8:1) than other LMWHs. Bemiparin 2,500 IU anti Xa/0.2 ml solution for injection in pre-filled syringes was provided for each patient in the heparin group; all patients were taught to self inject the medication subcutaneously once daily in the anterior abdominal wall or anterior aspect of upper thigh until 36 weeks of gestation.

ASPIRIN protect 100, BAYAR Company, (active ingredient: Acetyl Salicylic Acid $100 \mathrm{mg}$ coated tablets) was prescribed for the LDA group before pregnancy and continued till 36 weeks gestation.

Side effects of both treatment groups like gastritis, vaginal bleeding, echymosis, and abruption placentae were recorded.

\section{Ethical approval}

The study was approved by the scientific committee in the Maternity teaching hospital and the patients gave their written informed consent after full explanation of the aims of the study and confidentiality was approved.

Statistical analysis

Statistical analysis was conducted using the Statistical Package for Social Sciences (SPSS version 18). Data were described using mean, standard deviation for contentious 
variables and proportions for categorical variables. Independent $t$ test was used to analyze the difference between 2 meanvalues. Levene's test was used for equality of variance. Chi-square test was used to analyze the difference between proportions. A $P<0.05$ was considered statistically significant.

\section{Results}

Baseline characteristics

A total of 141 women were enrolled in this study, with 61 ladies assigned to receive Low dose Aspirin (LDA) and 80 cases assigned to LMWH (Bemiparin). Table 1 shows the baseline characteristics of participants according to the treatment groups (Table 2).

The mean age of the women who received LDA was $30.61 \pm 6.325$ years and the mean age of women who received Bemiparin was $31.44 \pm 5.811$ years. The mean parity in LDA group was $1.02 \pm 1.478$ while in the Bemiparin group the mean parity number was $1.29 \pm$ 1.398. The mean number of preceding abortions was

Table 1 Shows the baseline characteristics of participants according to treatment groups

\begin{tabular}{|c|c|c|c|}
\hline Characters & $\begin{array}{l}\text { Low dose } \\
\text { aspirin (LDA) }\end{array}$ & $\begin{array}{l}\text { Low molecular } \\
\text { weight heparin } \\
\text { (Bemiparine) }\end{array}$ & $P$ value \\
\hline Mean age (year) & $30.61 \pm 6.325$ & $31.44 \pm 5.811$ & 0.425 \\
\hline \multicolumn{4}{|l|}{ Age classes } \\
\hline$\leq 30$ year & $32(52.45 \%)$ & $34(42.5 \%)$ & \\
\hline$>30$ year & $29(47.54)$ & $46(57.5 \%)$ & \\
\hline Abortion history & & & 0.650 \\
\hline$\geq 3$ year & $41(67.21 \%)$ & $58(72.5 \%)$ & \\
\hline$<3$ & $20(32.78 \%)$ & $22(27.5 \%)$ & \\
\hline Mean nb. of abortion & $3.41 \pm 1.76$ & $3.28 \pm 1.72$ & \\
\hline Parity & & & 0.271 \\
\hline$\leq 1$ & $35(57.37 \%)$ & $35(43.75 \%)$ & \\
\hline$\geq 2$ & $26(42.62)$ & $45(56.25 \%)$ & \\
\hline Mean parity nb. & $1.02 \pm 1.478$ & $1.29 \pm 1.398$ & \\
\hline
\end{tabular}

$3.4 \pm 1.76$ in LDA group versus $3.28 \pm 1.72$ in Bemiparin group.

The primary aborters (P0) in the LDA group was 57.4 versus $42.6 \%$ of cases who presented with a secondary abortion (patients with previous successful deliveries), while in the Bemiparin group $43.8 \%$ of cases were primary aborters and $56.35 \%$ of cases presented with secondary abortion; this difference was statistically not significant between the two treatment groups. Using contingency coefficient test $(P$ value $=0.16)($ Table 2$)$.

Mode of delivery

About two-thirds of women in the LDA and Bemiparin groups gave birth to live infants through vaginal delivery (61 and 62\%, respectively) (Table 3).

About one-third of cases in both treatment groups delivered abdominally (38.63\% in LDA group vs. $37.1 \%$ in Bemiparin group); the indications for Cesarean sections were all based on obstetrical indications as revealed in Table 4.

Using Levine's test for equality of variance and $t$ test for equality of means regarding the indications for cesarean section in both treatment groups, with 95\% confidence interval, the mean difference was 0.63 , lower limit 0.515 , upper limit 0.64 , and a standard error difference 0.29 (Table 5); there was no difference between the two groups regarding the indications for cesarean section.

\section{Outcomes}

There was a statistically significant difference between the two treatment groups regarding live birth rate. The

Table 3 Distribution of cases according to the mode of delivery

\begin{tabular}{lllc}
\hline $\begin{array}{l}\text { Mode of } \\
\text { delivery }\end{array}$ & $\begin{array}{l}\text { Low dose } \\
\text { aspirin group }\end{array}$ & $\begin{array}{l}\text { Low molecular } \\
\text { weight heparin } \\
\text { (Bemiparin) }\end{array}$ & $P$ value \\
\hline Vaginal delivery & $27(61.36 \%)$ & $44(62.85 \%)$ & 0.99 \\
Cesarean section & $17(38.63 \%)$ & $26(37.14 \%)$ & \\
Mean difference & $1 \pm 0.753$ & $1.20 \pm 0.644$ & \\
\hline
\end{tabular}

Table 2 Distribution of cases according to history of successful deliveries

\begin{tabular}{|c|c|c|c|c|c|c|}
\hline & \multicolumn{6}{|l|}{ GRP } \\
\hline & \multicolumn{2}{|l|}{ ALD } & \multicolumn{2}{|c|}{ Bemiparin } & \multicolumn{2}{|l|}{ Total } \\
\hline & Count & Total N (\%) & Count & Total N $(\%)$ & Count & Total N (\%) \\
\hline Primary aborters (P0) & 35 & 57.4 & 35 & 43.8 & 70 & 49.6 \\
\hline Secondary aborters $(P \geq 1)$ & 26 & 42.6 & 45 & 56.3 & 71 & 50.4 \\
\hline Total & 61 & 100.0 & 80 & 100.0 & 141 & 100.0 \\
\hline
\end{tabular}


proportions of women who gave birth to a live infant were $72.13 \%$ in the LDA group and $86.25 \%$ in the Bemiparin group, the mean difference between the live birth rate in both groups was 0.141 (95\% Confidence interval of the difference was, lower limit 0.08 and, upper limit 0.274). All newborns in the sample size were singleton babies (Table 6).

In an analysis involving women who gave birth to live infants, the average birth weight for women was received LDA was significantly lower than those who received Bemiparin (Table 6).

Normalization of birth weight in both groups using Levene's test for equality of variance showed a highly significant difference regarding the gestational age ( $P$ value, 0.000$)$, but there was no significant variance regarding parity $(P$ value, 0.747$)$ as revealed in Table 7.

Table 4 Distribution of cases according to indications for cesarean section

\begin{tabular}{|c|c|c|c|c|}
\hline & \multicolumn{4}{|l|}{ GRP } \\
\hline & \multicolumn{2}{|l|}{ LDA } & \multicolumn{2}{|c|}{ Bemiparin } \\
\hline & Count & $\begin{array}{l}\text { Column } \\
\text { Total N } \\
(\%)\end{array}$ & Count & $\begin{array}{l}\text { Column } \\
\text { Total N } \\
(\%)\end{array}$ \\
\hline $\begin{array}{l}\text { Abortion and vaginal } \\
\text { delivery }\end{array}$ & 44 & 72.1 & 55 & 68.8 \\
\hline \multicolumn{5}{|c|}{ Indications for cesarean section } \\
\hline Fetal malpresentation & 4 & 6.6 & 7 & 8.8 \\
\hline $\begin{array}{r}\text { Cephalopelvic } \\
\text { disproportion }\end{array}$ & 1 & 1.6 & 5 & 6.3 \\
\hline Fetal distress in labor & 4 & 6.6 & 5 & 6.3 \\
\hline $\begin{array}{l}\text { Failure to progress in } \\
\text { labor }\end{array}$ & 3 & 4.9 & 3 & 3.8 \\
\hline Poor obstetric history & 2 & 3.3 & 3 & 3.8 \\
\hline Previous C-section & 3 & 4.9 & 2 & 2.5 \\
\hline Total & 61 & 100.0 & 80 & 100.0 \\
\hline
\end{tabular}

Failed treatment in both groups resulted in miscarriages in the first trimester before 10 weeks of gestation.

\section{Maternal and fetal complications}

All participants in the two treatment groups delivered after 37 weeks of gestation except two cases in the LDA group and three case in the Bemiparin group who delivered at 32 weeks of gestation (preterm labor), the difference was statistically not significant $(P$ value $>0.05)$. The preterm infants were admitted to the neonatal intensive care unit in the Maternity Teaching Hospital and discharged after 1 week in a good condition.

There were no cases of maternal embolic event during pregnancy or in the postpartum period in both treatment groups. One woman in the Bemiparin group developed severe preeclampsia. This woman had type 1 diabetes mellitus and was on insulin. She was 24 years old with a history of diabetes for 10 years; her blood sugar was strictly controlled in all her previous pregnancies, which ended in miscarriages in the first trimester. Blood test for anticardiolipin antibody was high on more than two occasions, for that reason she was included in our trial being a case of APS rather than an uncontrolled diabetes causing RM.

Five cases out of 80 in the Bemiparin group presented with slight ecchymosis at the injection site.

Table 6 Distribution of cases according to live birth rate and fetal weight in both groups

\begin{tabular}{llll}
\hline & $\begin{array}{l}\text { Low dose aspirin } \\
\text { group }\end{array}$ & $\begin{array}{l}\text { LMWH } \\
\text { (Bemiparin) group }\end{array}$ & $P$ value \\
\hline Live birth rate & $44(72.13 \%)$ & $69(86.25 \%)$ & 0.045 \\
$\begin{array}{l}\text { Mean fetal } \\
\text { weight }(\mathrm{kg})\end{array}$ & $2.323 \pm 1.50$ & $3.129 \pm 1.263$ & 0.001 \\
\hline
\end{tabular}

Table 5 Difference between the two groups regarding indications for cesarean section

\begin{tabular}{|c|c|c|c|c|c|c|c|c|c|}
\hline \multirow[t]{3}{*}{ Indication for cesarean section } & \multicolumn{2}{|c|}{$\begin{array}{l}\text { Levene's test for equality of } \\
\text { variances }\end{array}$} & \multicolumn{7}{|c|}{$t$ test for equality of means } \\
\hline & \multirow[t]{2}{*}{$\mathrm{F}$} & \multirow[t]{2}{*}{ Sig. } & \multirow[t]{2}{*}{$\mathrm{T}$} & \multirow[t]{2}{*}{$d f$} & \multirow[t]{2}{*}{$\begin{array}{l}\text { Sig. } \\
\text { (2-tailed) }\end{array}$} & \multirow[t]{2}{*}{$\begin{array}{l}\text { Mean } \\
\text { difference }\end{array}$} & \multirow[t]{2}{*}{$\begin{array}{l}\text { Std. error } \\
\text { difference }\end{array}$} & \multicolumn{2}{|c|}{$\begin{array}{l}95 \% \text { Confidence } \\
\text { interval of the } \\
\text { difference }\end{array}$} \\
\hline & & & & & & & & Lower & Upper \\
\hline Equal variances assumed & 0.668 & 0.415 & 0.220 & 139 & 0.826 & 0.06332 & 0.28793 & -0.50598 & 0.63261 \\
\hline Equal variances not assumed & & & 0.217 & 121.021 & 0.829 & 0.06332 & 0.29243 & -0.51562 & -0.64226 \\
\hline
\end{tabular}


Table 7 Normalization of birth weight in both groups regarding gestational age and parity

\begin{tabular}{|c|c|c|c|c|c|c|c|c|c|}
\hline & & \multicolumn{2}{|c|}{$\begin{array}{l}\text { Levene's test for } \\
\text { equality of variances }\end{array}$} & \multicolumn{6}{|c|}{$t$ test for equality of means } \\
\hline & & \multirow[t]{2}{*}{$\mathrm{F}$} & \multirow[t]{2}{*}{ Sig. } & \multirow[t]{2}{*}{$\mathrm{T}$} & \multirow[t]{2}{*}{ Sig. (2-tailed) } & \multirow[t]{2}{*}{$\begin{array}{l}\text { Mean } \\
\text { difference }\end{array}$} & \multirow[t]{2}{*}{$\begin{array}{l}\text { Std. error } \\
\text { difference }\end{array}$} & \multicolumn{2}{|c|}{$\begin{array}{l}95 \% \text { confidence } \\
\text { interval of the } \\
\text { difference }\end{array}$} \\
\hline & & & & & & & & Lower & Upper \\
\hline \multirow[t]{2}{*}{ Gestational age } & Equal variances assumed & 330.340 & 0.000 & 12.172 & 0.000 & 24.043 & 1.975 & 20.138 & 27.949 \\
\hline & Equal variances not assumed & & & 10.633 & 0.000 & 24.043 & 2.261 & 19.521 & 28.566 \\
\hline \multirow[t]{2}{*}{ Parity } & Equal variances assumed & 0.104 & 0.747 & -1.113 & 0.268 & -0.271 & 0.244 & -0.753 & 0.210 \\
\hline & Equal variances not assumed & & & -1.105 & 0.271 & -0.271 & 0.245 & -0.757 & 0.215 \\
\hline
\end{tabular}

\section{Discussion}

In this trial we found that the use of the new second generation LMWH (Bemiparin) in patients with history of RM due to APS improves the live birth rate in comparison to LDA alone. The live birth rate was $86.25 \%$ in the LMWH group versus $72.13 \%$ in the LDA alone group.

The present standard of care for women with aPL and RPL is treatment with heparin and low dose aspirin [17]. There have been a number of randomized control trials for patients with RPL due to aPL evaluating either unfractionated heparin (UFH) or LMWH over the past 15 years. Each trial determined its inclusion criteria; however, regardless of differences in aPL status among the various trials, the live birth rates were similar ranging from 71.1 to $84 \%$. The only significant differences among trial outcomes were in the LDA-only treatment arms: the live birth rates in those varied from a low of $42.2 \%$ to a high of $80 \%$ [18].

To date, studies confirmed that treatment with LMWH plus LDA should be considered as the standard therapy for recurrent pregnancy loss due to aPL [19, 20]. All these previous studies used previously wellknown LMWH like Enoxaprin. Also, there were many studies also using heparin alone or in combination with LDA with different success rates regarding live birth rate. Using a new LMWH in the current trial, we suspect the results to be similar to the reults of previous published trials using other LMWHs.

Bemiparin was the first LMWH to be marketed in our city since 2007; formerly UFH was available with unrecognized sources because of the political problems of Iraqi people.

Our trial is regarded as the first to be published on pregnant ladies receiving Bemiparin from the time of diagnosis of pregnancy and up to 36 weeks of gestation, and having a success rate of $86 \%$ in cases of APS associated with RPL.

There were no major adverse events associated with both treatment arms and this result was in agreement with an RCT done by Carl et al. to compare live birth rates in women with RPL and either autoantibodies or a coagulation abnormality, treated with heparin plus aspirin (LMWH/ASA) or ASA alone [19].

The mean birth weight for newborns was higher in the Bemiparin group. Because there was no head-to-head study comparing LMWH (Bemiparin) versus LDA for prevention of RPL in the first trimester due to APS, the relative effect of Bemiparin versus LDA regarding birth weight is unknown.

Regarding the single case with type 1 diabetes and being positive to APS, type 1 diabetes is an indicator of immune dysregulation that develops as a result of an autoimmune process. It has been reported that patients with type 1 diabetes have a high level of aCL antibodies as a marker of autoimmune dysregulation [21]. Future research may concentrate on cases with good diabetes control but still present with RM to investigate for other types of autoantibodeis that may be responsible for the recurrent pregnancy losses.

There were some limitations in the current study that warrant consideration. The study was stratified by the presence of acquired autoantibody syndrome (APS); by checking for only aPL, inherited thrombophilia was not tested for in the sample size. We consider it appropriate to test for a boarder spectrum of autoantibodies in patient presenting with RPL.

The current study included women with a history of two or more consecutive first trimester miscarriages, depending on the definition used by the American College of Obstetrics and Gynecology [2] rather than the definition of three or more miscarriages [6], which is used traditionally to define RM. This may have theoretically diluted the result of the trial. Trials on RPL and the use of different treatment protocols abroad show that the selection of cases according to the history of previous miscarriages differ from two to three RPL with no significant difference concluded in the results depending on the previous number of miscarriages $[18,22]$. Also there was no difference in the pregnancy outcome in women having a history of less than and more than three pregnancy losses in both treatment arms in the current trial. 
Our study was an open label RCT; the patients were randomly assigned to each treatment group, but they were then made aware of the group to which they were assigned taking into consideration that the ethical concern of subjecting pregnant women to daily placebo injection for 36 weeks gestation is in favor of using an open label design.

The use of LDA is on the basis that it is a wellknown antiplatelet drug that has been used in many previous and update trials alone or in combination with heparin in cases of RPL due to APS; its use was either as a treatment arm or as a control group to compare the efficacy of the new heparin.

Although the live birth rate of the current study was high, further research is needed using larger sample sizes, comparing the drug with a true control group and a combination of the drug with LDA.

\section{Conclusion}

The use of the new second generation LMWH (Bemiparin) in comparison to LDA during pregnancy for prevention of RM in women with APS is a safe, reliable method with a high live birth rate and no maternal and fetal complications.

Conflict of interest There is no conflict of interest in relation to the current article.

Open Access This article is distributed under the terms of the Creative Commons Attribution Noncommercial License which permits any noncommercial use, distribution, and reproduction in any medium, provided the original author(s) and source are credited.

\section{References}

1. Bricker L, Farquharson G (2000) Types of pregnancy loss in recurrent miscarriage: implications for research and clinical practice. Hum Reprod 17:1345-1350

2. Carson A, Branch W (2001) Management of recurrent early pregnancy loss, Compendium selected publications. American College of Obstetricians and Gynecologists, Washington, DC, pp 372-383

3. Rai R, Regan L (2006) Recurrent miscarriage. Lancet 368:601611

4. Clifford K, Rai R, Waston H, Regan L (1994) An informative protocol for the investigation of recurrent miscarriage: preliminary experience of 500 consecutive cases. Hum Reprod 9:1328-1332

5. Clark A (1999) Critically examining the immunologic causes of recurrent miscarriage. MedGenMed 1(3). Formerly published in Medscape Women's Health eJournal 4(3); 1999. Available at http://www.medscape.com/veiwarticle/405322
6. Jauniaux E, Farquharson G, Christiansen B, Exalto N (2006) Evidence-based guidelines for the investigation and medical treatment for recurrent miscarriage. Hum Reprod 21(9):22162222. Advance Access originally published online on May 17, 2006. Human Reproduction

7. Gautam A, Swati A (2003) Low molecular weight heparin in immunological recurrent abortion-the incredible cure. J Assist Reprod Genet 20:2

8. John H (2003) Antiphospholipid syndrome: an overview. Can Med Assoc J 168(13):1675-1682

9. Abaci A, Bober E, Yesikaya E, Bidec A, Cinaz P, Buyukgebiz A (2010) Prevalence of anticardiolipin antibodies in type 1 diabetes and autoimmune thyroiditis. Pol Arch Med Wew 120(3):71-75

10. De Wolf F, Carreras O, Moerman P, Vermylen J, Van A, Renaer M (1982) Decidual vasculopathy and extensive placental infarction in a patient with repeated thromboembolic accidents, recurrent fetal loss, and a lupus anticoagulant. Am J Obstet Gynecol 142(7):829-834

11. Walport J (1989) Pregnancy and antibodies to phospholipids. Ann Rheum Dis 48:795-797

12. Mehdi A, Uthman I, Khamashta M (2010) Treatment of antiphospholipid antibody Syndrome. Int $\mathrm{J}$ Clin Rheumatol 5(2):241-254

13. Out J, Kooijman D, Bruinse W, Derksen H (1999) Histopathological findings in placentae from patients with intra uterine fetal death and anti-phospholipids antibodies. Eur J Obstet Gynecol Reprod Biol 41:179-186

14. Dawes J, Bara L, Billaud E, Samma M(1986) Relationship between biological activity and concentration of a low molecular weight heparin (PK 10169) and unfractionated heparin after intravenous and subcutaneous administration. Haemostasis 16(116):122

15. Dulitzki M, Pauzner R, Langevitz P, Many A, Schiff E (1996) Low molecular weight heparin during pregnancy and delivery: preliminary experience with 41 pregnancies. Obstet Gynecol 87:380-383

16. Asherson A, Cervera R, de Groot G et al (2003) Catastrophic antiphospholipid syndrome: international consensus statement on classification criteria and treatment guidelines. Lupus 12(7):530534

17. Kutteh H (1996) Antiphospholipid antibody-associated recurrent pregnancy loss: treatment with heparin and low dose aspirin is superior to low dose aspirin alone. Am J Obstet Gynecol 174:1584-1589

18. Carla A, Karen A, Christine A, Mark R, Jeff S et al (2009) Low molecular weight heparin and aspirin loss: result from the randomized, controlled HepASA trail. J Rheumatol. doi: 10.3899/jrheum.080763. Published online before print February 4

19. Triolo G, Ferrante A, Ciccia F, Accardo-Palum A, Perino A et al (2003) Randomize study of subcutaneous low molecular weight heparin plus aspirin versus intravenous immunoglobulin in the treatment of recurrent fetal loss associated with antiphospholipid antibodies. Arthritis Rheum 48(3):728-731

20. Royal College of Obstetrician and Gynaecologists (2003) The investigation and treatment of recurrent miscarriage [internet], Guideline No 17. London: RCOG Press, 2003 May [cited 2009 Feb 8]. $13 \mathrm{p}$

21. Mohamed M, Abdou O, Assem M, Mustafa M, Soghier M (2002) Anticardiolipin antibodies in children with insulin dependent diabetes mellitus. Metabolism. 51:1148-1152

22. Stef K, Mariette G, Joris M, Van P, Barbara H et al (2010) Aspirin plus heparin or aspirin alone in women with recurrent miscarriage. N Engl J Med 362:1586-1596 